Annals of Tropical Research 33(1): 19-30 (2011)

\title{
Definition of Forest for REDD+: an Unresolved Issue
}

\author{
Medrilzam and Paul Dargusch \\ School of Agriculture and Food Sciences \\ The University of Queensland, Brisbane, QLD 4072, Australia
}

\begin{abstract}
Debate over arrangements for REDD+ in a post-Kyoto climate policy framework has been continuing in United Nations Framework Convention on Climate Change (UNFCCC) negotiations; however, no review of the applicability of the existing forest definition to future REDD+ implementation has been undertaken. This paper highlights the need to review the definition of forest, and examines proposals to improve existing definitions. The impacts of the current forestry definition are discussed with reference to Indonesia as a case study. It is concluded that careless definition of selected forest-related terms has had a negative impact on Indonesia's involvement in the implementation of Clean Development Mechanism (CDM) afforestation and reforestation (A/R) projects. In the global context, this paper concludes that there should be clear definitions for definition of forest that are flexible enough to accommodate the various interests of UNFCCC parties. At the national level, each country should specify their forest definition carefully, taking into consideration the guidance provided at the global level and its own forest characteristics and management. Failing to do so can limit the involvement of these nations in future REDD+ schemes and reduce their capacity to mitigate climate change impacts.
\end{abstract}

Keywords: deforestation, degradation, CDM A/R, UNFCCC

\section{INTRODUCTION}

Negotiation on Reduced Emissions from Deforestation and forest Degradation Plus $(\mathrm{REDD}+)^{1}$ as a future climate change mitigation option for the period beyond the expiration of the Kyoto Protocol (known as the post-2012 Framework) has been

${ }^{1}$ Reduced Emissions from Deforestation and forest Degradation (REDD) is a climate change mitigation scheme in the forestry sector that was initially proposed by developing countries at COP11 of the UNFCCC in 2005. REDD is proposed to be implemented fully in a post-2012 framework (the second commitment period of the Kyoto Protocol). The plus sign indicates that the scheme's scope is broader than just avoided deforestation as was originally proposed, and includes reducing emissions from forest degradation, conservation of forest carbon stocks, sustainable management of forests, and enhancement of forest carbon stocks. 
considered a promising result of the 15th Conference of Parties (COP15) to the UNFCCC at Copenhagen in 2009 (Bleaney et al., 2010). This positive achievement was continued in Cancun 2010 where there was a formal agreement reached at COP16 that includes the overall goals, scope, approach and safeguarding mechanism of REDD+, while remaining undecided on implementation of safeguards, strategy, financial mechanism, and emission reduction targets of REDD+, to be discussed in next few rounds of negotiations (Morgan et al., 2010).

Fundamental issues concerning forest-related definitions have been ignored in the latest rounds of UNFCCC negotiations including the appropriate definition of 'forest' for REDD+ activities. Forest definition is important for REDD+ because it has implications for the suitability of an area for a REDD+ activity. This suitability condition could be influenced by a range of factors including legal status and ownership, management of the area, and physical forest conditions. Failure to define 'forest' clearly will have consequences - for example the vague status of landownership (land tenure), unclear management and the boundaries of the REDD+ area - which could further lead to uncertain conditions for any investment in REDD+. Another issue related to forest definition is the measurement and comparison of carbon stocks in REDD+ areas in various time periods. Different definitions of 'forest' might produce different estimated quantities of carbon stocks that could complicate the measurement of baselines, Reference Levels (RL), Reference Emission Levels (RELs) and REDD+ credit in the future. Efforts made to aggregate carbon stock estimates from REDD+ activities for the purpose of reporting at the national or international level might also be affected by choice of definition. Different definitions of 'forest' between regions or countries could result in non-comparable forest data among regions or countries (Helms, 2002). Therefore, it would be difficult later for the UNFCCC or countries to develop an integrated report on the results of greenhouse gas emission reductions efforts from various REDD+ that use different forest definitions. Because the Measurement, Reporting and Verification (MRV) mechanism will be implemented in the post-Kyoto framework, adoption of a common definition of 'forest' will be needed to allow aggregation of carbon stocks and to measure and compare efforts in REDD+ areas across countries or regions.

The definition of 'forest' is one of the topics in the methodological negotiations that have been mostly discussed under the Subsidiary Body of Science and Technology Assessments (SBSTA) of the UNFCCC. Considering the latest negotiation text (in Copenhagen, December 2009 and in Cancun, December 2010), the item of forest definition and other methodological aspects such as drivers of deforestation have been set aside. The current text only emphasizes and 'approves' the 2006 IPCC guidance, and further supports the capacity building program for developing countries to use this guidance. No further clarification on which forest definition will be used for REDD+ implementation is included in the SBSTA decision. This potentially creates different interpretations among countries, and even the project proponents, of what should or should not be done in REDD+ projects.

This paper describes the debates over forest definitions and how these definitions can be applied for the REDD+ scheme. Descriptive analysis is used to reveal several proposals on forest definition, including the advantages and disadvantages of those proposed definitions. In this paper, Indonesia's example of defining 'forest' has been 
taken as a case study of how forest definition can affect the involvement of the country in the Clean Development Mechanism (CDM) afforestation and reforestation $(\mathrm{A} / \mathrm{R})$ scheme, and potentially in future REDD+ implementation.

\section{DEBATES OVER FOREST DEFINITIONS}

To date there has been no international agreement on what constitutes a forest. Most differences in definitions are based on the emphases or concerns of various stakeholders derived from their value systems and modes of interaction with forests. Even for forests that have similar characteristics, definitions of 'forest' are likely to vary. Political considerations may influence these distinctions. For example, definition of 'forest' in a broader term could allow the government to take advantage on any forest schemes that provide greater benefit. It is also the case that in domestic contexts many regional governments use different 'forest' definitions. Lambrechts et al. (2008) noted that people typically define 'forest' based on factors including latitude, rainfall patterns, temperature, soil composition and human activity. These authors also argued that some definitions are determined by the scope and purpose of activities, or by the goals of institutions or countries. For example, the 'forest' definition for accounting purposes that emphasizes forest cover might be different from the forest definition used by the biologist who underlines the importance of the ecosystem boundary.

Helms (2002) and Lund (2009) found that many countries and institutions use quantitative indicators to define a forest, such as the percentage of forest crown cover, height and diameter of trees, and forest size while others define qualitative indicators such as legal ownership or administrative unit and ecosystem functions. Lund also collected meta-data information and found that there are at least 950 'forest' definitions around the world. In his other work, Lund (2005) also noted that some countries (including the USA) and some UN agencies use different 'forest' definitions simultaneously.

In the climate change context, the current definition of 'forest' used by the UNFCCC derives mainly from negotiation between Parties in the Kyoto Protocol framework. 'Forest' is defined as:

'a minimum area of land of $0.05-1.0$ hectares with tree crown cover (or equivalent stocking level) of more than 10-30 per cent with trees with the potential to reach a minimum height of 2-5 metres at maturity in situ. A forest may consist either of closed forest formations where trees of various storeys and undergrowth cover a high proportion of the ground or open forest. Young natural stands and all plantations which have yet to reach a crown density of 10-30 per cent or tree height of 2-5 meters are included under forest, as are areas normally forming part of the forest area which are temporarily unstocked as a result of human intervention such as harvesting or natural causes but which are expected to revert to forest (UNFCCC, 2001, p.58)'.

This definition is being used by the Parties to implement the Clean Development Mechanism (CDM) in the LULUCF (Land Use, Land Use Change and Forestry) sector through afforestation and reforestation (A/R) activities. The criteria of forest definition (area, tree crown cover, height) were originally taken from the FAO's forest 
definition in 2000. However, ranges of minimum parameter values in the Kyoto Protocol forest definition are provided to accommodate varying forest conditions in host countries. In 2005, the FAO changed its forest definition to state that a forest has at least $10 \%$ canopy cover of a tree height of more than $5 \mathrm{~m}$ in at least 0.5 ha of land (FAO, 2006).

In the context of REDD+ negotiations, there has been no 'forest' definition agreed upon to date. Environmentalists (e.g. Cadman, 2008; Van Noordwyk, 2008; Sazaki and Putz, 2009) have argued that the current definition of forest, either the FAO definition (FAO, 2006) or the Kyoto Protocol definition (UNFCCC, 2001), is not suitable for REDD+ purposes. There are four main arguments from those authors that relate to the limitations of current forest definition as discussed further below.

First, the UNFCCC forest definition fails to differentiate between natural forests and industrial tree plantations (Cadman, 2008). According to the definition of land use used by the FAO and accepted by most governments, forestland that has been harvested or clear-cut is not regarded as deforested because, in principle, trees may regrow or be replanted. Deforestation is recorded only when the land is permanently converted to non-forest use. This creates the risk that governments and companies could replace forests - natural or primary or pristine forests - with oil palm, eucalypts or rubber plantations and claim carbon credits under REDD+ schemes.

Second, Sasaki and Putz (2009) argued that the minimum benchmarks for quantitative indicators including percentage crown cover, area of tree domination and height of trees in Kyoto Protocol's forest definition, are too low and should be raised Natural forests typically have a higher canopy cover than this range. The possibility exists that exploitative logging companies could log a substantial volume of trees within a natural forest and leave a severely degraded forest that still meets the UNFCCC standard. For this reason, Sasaki and Putz (2009) proposed to apply a minimum $40 \%$ crown cover and $5 \mathrm{~m}$ tree height for REDD+ implementation.

Third, the current definition of forest also fails to include forest degradation, thus ignoring the substantial emissions occurring as a result of this process (Sasaki and Putz, 2009). Forest degradation diminishes forest carbon storage and other ecosystem services, usually increases the risk of fire, and reduces biodiversity. Even though the IPCC (2006) has attempted to define forest degradation as a long-term loss of forest carbon stocks in a forest area not qualifying as deforestation due to direct human influences, it has not defined criteria on the length of time and the amount of carbon storage lost in a forest area.

Fourth, Van Noordwijk (2008) argued that the current forest definition also fails to identify potential carbon stocks and sinks in a 'green' area matched with UNFCCC or FAO forest definitions but located outside of a forest management boundary. He argued that many non-forest 'green' terrestrial (such as agro-forestry and peatland) areas that contain large carbon stocks are located and grown outside of 'forest domain' management. He further suggested applying the whole landscape approach for REDD+ instead of targeting the forest area only.

The four arguments above have both strengths and weaknesses. Forest definitions agreed to by the FAO and Kyoto Protocol parties resulted from a long process of negotiation, and attempted to accommodate various interests and forest conditions in all countries. The Kyoto Protocol forest definition was originally established for the 
purpose of GHG emission reduction in the forest sector, leaving aside other issues such as biodiversity, indigenous people and poverty. The Kyoto Protocol's forest definition is not used to determine whether forest is primary, secondary or plantation forest. Therefore, any matters on the definition additional to carbon issues will potentially intensify the difficulties in implementing forest-carbon initiatives under the Protocol.

The inclusion of forest plantations in the Kyoto Protocol implementation as opposed by Sazaki and Putz (2009) was actually expected not only to benefit developed countries, but also to benefit developing countries that were conducting $\mathrm{A} / \mathrm{R}$ programs. There are many private and state forest plantations operating forest plantations at the moment in developing countries and they could possibly benefit from the A/R CDM provided all prerequisites of the scheme are fulfilled. Under the REDD+ scheme, the inclusion of forest plantations might be possible inside the scope of the 'Sustainable Management of Forest'. The application of Reduced Impact of Logging (RIL) activities inside forest plantations could possibly reduce the carbon emission in the logging and plantation operators and support the objective of the sustainable management of forest under the REDD+ scheme. However, concerns about RIL applications have been raised by Putz et al. (2000) because many logging operators in developing countries remain reluctant to implement RIL. Rosoman et al. (2009) added some concerns over RIL applications for primary forest because any logging operations in primary forests would be likely to cause degradation. Nonetheless, the UNFCCC parties have accommodated concerns about the possibility of converting primary forest through logging and forest plantation operations under REDD+. They decided to include the prohibition of primary forest conversion in the REDD+ safeguarding decision as stated in Appendix I of UNFCCC decision 1/16:

'... 2(e) Actions, that are consistent with the conservation of natural forests and biological diversity, ensuring that the actions referred to in paragraph 70 of this decision [note: REDD+] are not used for the conversion of natural forest, but are instead used to incentivize the protection and conservation of natural forests and their ecosystem services, and to enhance other social and environmental benefits.' (UNFCCC, 2010)'.

The UNFCCC, however, still seems to support flexibility in accommodating various forest management practices. Therefore, to accommodate the interests of developed countries in including forest plantations as part of REDD+, UNFCCC parties agreed to the inclusion of enhancement of 'carbon stocks and sustainable management of forests' as one of the REDD+ scopes. This implied the possibility of including forest plantations in future REDD+ implementation. To address concerns about the adverse effects of logging and forest plantation operation in REDD+ implementation, UNFCCC parties also agreed to secure and emphasize a safeguarding policy on protection of biodiversity and indigenous people and poverty aspects (UNFCCC, 2010) in their decision at Cancun in 2010. The safeguarding mechanism mentioned in UNFCCC (2010) includes protection of primary forest, governance and involvement of local and indigenous people. 
Regarding the low quantitative standards applied to forest conditions, the concern of Sasaki and Putz (2009) might only be valid for REDD+ application in primary forests in the tropical forest countries. The countries, that own secondary forests as their majority, will not have any difficulties meeting the low benchmarks of current forest definitions. Current definitions will allow these countries to effectively develop forest plantations in secondary forests. In terms of carbon stock savings, with a combination of well managed RIL and sustainable forest management, the current forest definition might be suitable for REDD+ in secondary forest areas although the current definitions neglect the potential threat of forest degradation to the accumulation of carbon stocks. However, there are still technical limitations when measuring carbon loss from forest degradation and costs associated with this assessment. These limitations might create barriers to include degraded forests on the definition of 'forest' in the climate change mitigation context. Nevertheless, it is expected that advances in remote sensing technology will eliminate this difficulty.

The proposal by Noordwijk (2008) for the inclusion of non-forest areas into the REDD+ scheme will actually create another strand of complexity for REDD+ negotiations. Traditionally, many forest definitions globally refer to a specific boundary of the area to be managed. Furthermore, the original idea of REDD+ was to solve issues in forest management, not in other land use management. If the suggestion of including agriculture, forestry and other land use (AFOLU) - or in the Noordwijk et al. (2010) terms of Reducing Emission from All Land Uses (REALU) in the calculation or measurement of REDD+ is accepted, the REDD+ scheme will become extremely complex, and possibly create another hurdle that impedes the forestry component of UNFCCC negotiation. For the sake of simplicity and to speed up negotiations in the REDD process, the inclusion of agriculture and other land use outside of forest areas should be put aside to allow REDD+ activities to be implemented as soon as possible. Meanwhile, all preparations to include important agricultural and other land uses can be managed in a separate parallel process outside of UNFCCC negotiation. Non-forestry land based sectors could be incorporated into the REDD+ scope when the sectors are ready for implementation.

Cadman (2008) proposed to differentiate between natural and plantation forest instead of changing the existing forest definitions. He defined natural forest as a terrestrial habitat for biodiversity produced through a long evolutionary process and preserved by nature, and plantations as comprising trees that are regularly planted and harvested and which do not provide appropriate conditions for biodiverse habitats. He further argued that a plantation is an agricultural activity, not a forestry activity. As REDD+ is a forestry activity, this statement implies that plantations should be excluded in future REDD+ implementation. This argument is based on the opinion that forests must be protected due to biodiversity considerations, and that forest definition does not seem to have a strong linkage with carbon stocks. Moreover, this argument ignores the traditional forest definition that emphasizes 'domination of trees' as the main characteristic of a forest. It is likely that this type of definition would be opposed by developed countries and developing countries that have been engaged in plantation forestry for a long period of time.

Discussing a new definition for 'forest' could result in an endless debate. Even though Noordwijk (2008) and Sasaki and Putz (2009) proposed to discuss a forest 
definition which is applicable for future REDD+ implementation, a compromise solution for forest definition on future REDD+ implementation is actually not to debate on a common definition of forest, as Cadman (2008) suggested, but rather to differentiate treatment in REDD+ mechanisms for primary, secondary and plantation forests. This proposal is similar to Cadman's proposal but with differences in the scope and treatment of REDD+ activities. These forest types are eligible for REDD+. To assuage concerns over aspects other than trees, the differentiated treatment of primary, secondary and plantation forest in the REDD+ mechanism will allow parties to accommodate their interests according to their own existing forest conditions. REDD+ implementation in a primary forest certainly does not allow any plantation or logging operation to benefit from a REDD+ scheme. REDD+ investment in primary forest will only be dedicated to avoided deforestation activities in order to protect and secure the existence of the primary forest. In secondary forests, REDD+ investment can be allocated for avoided deforestation as implemented in primary forest, but it also allows the plantation to implement techniques such as RIL to minimize forest degradation. On the plantation side, operators can be provided with options to improve degraded forest or replant the forest to enhance carbon stocks. This differentiation would allow future REDD+ implementation benefits for both developing countries and developed countries, and even conservationist and plantation groups. This differentiation could also provide flexibility of future REDD+ depending on how implementation is designed and negotiated. As a consequence, the parties are allowed to develop their own forest definition for REDD+ implementation, even though this could create difficulties in global reporting, particularly in aggregating efforts undertaken by all parties.

To avoid any unnecessary impact of REDD+ implementation, parties need a strong safeguarding REDD+ policy (Sazaki and Putz, 2009) which is created through a transparent process, both internationally and nationally, and which allows independent reviewers to evaluate the success of REDD+ implementation. Regardless of which definition of 'forest' is applied for particular countries, the safeguarding policy is expected to play a role in ensuring that REDD+ investment does not abuse the environmental integrity of any carbon emission reductions and removals from forestry. The UNFCCC parties in 2010 eventually agreed on the safeguarding policies on REDD+ (UNFCCC 2010). Therefore concerns on having various definition of forest might be set aside as long as the safeguarding policies are consistently applied in REDD+ implementation.

\section{Implication of Current UNFCCC's Forest Definition: the Case of Indonesia's Forests}

According to Forestry Law no. 41/ 1999, Indonesia defines 'forest' as ' ... a unit of ecosystem in the form of lands comprising biological resources, dominated by trees in their natural forms and environment, which cannot be separated each other'. This law also states that any watersheds, islands or regions must have at least $30 \%$ tree crown cover of forest. Furthermore, it affirms that the regions which have forest cover of more than $30 \%$ should maintain this figure and may not reduce it to the minimum, while the regions which have less than $30 \%$ tree crown cover of forest must make 
strong efforts to attain this limit by carrying out forest rehabilitation and reforestation activities.

Following ratification by Indonesia of the Kyoto Protocol in 2004, the Ministry of Forestry released Regulation No. P.14/Menhut-II/2004 on Guidance of Afforestation and Reforestation under the Clean Development Mechanism (CDM A/R). In this regulation, it was stated that Indonesia considers an area of 0.25 ha, 30\% tree crown cover and 5 meters in height as the minimum criteria for forest definition applied to any CDM A/R project implementation. This regulation also copied the Kyoto Protocol definition of afforestation and reforestation which defined conversion of land without forest for 50 years or more to forestland as afforestation, and conversion of land deforested before 31 December 1989 to forestland as reforestation. Further exacerbating complex CDM procedures being applied by the UNFCCC, which would further reduce the interest of many carbon players to invest in CDM A/R in Indonesia, the Kyoto Protocol definition of afforestation and reforestation has become a substantial barrier to Indonesia implementing CDM A/R, particularly in finding eligible land. Selection of these criteria, in particular the 1990 base year, and the restrictive forest definitions, have limited or reduced the eligibility of various types of Indonesian forest to participate in CDM A/R projects. The most heavily logged areas of low tropical forest were deforested beginning in the 1970s, and most of those land areas degraded in Indonesia prior to 1990 were still categorized as forest areas, and hence do not meet the Kyoto Protocol definition of reforestation. Furthermore, in Indonesia only private land is eligible for afforestation because there has been no accurate information available on state forestland for the past 50 years. This definition problem has exacerbated the barriers to Indonesia's participation in CDM A/R, and as Neeff et al. (2006) pointed out, weak and careless choice of definitions could affect eligibility, extent, prospects and impacts of forestry-based CDM projects. In fact, no CDM A/R project has yet been submitted to the CDM Executive Board by Indonesia.

The Government of Indonesia intends to carefully define forest terminologies for REDD+, including deforestation, degradation and REDD+. Having at the time had no guidance on forest definitions for REDD+ globally, in 2009 the Ministry of Forestry released a Regulation No. P.30/Menhut-II/2009 about the REDD Mechanism. A similar forest definition to that in Law no. 14/ 1999 is used for future REDD+ implementation in this regulation. This definition is rather flexible and Indonesia seems not to limit various opportunities provided by future REDD+ investment. All Indonesian forest types which have faced the threat of being converted to nonforestland are eligible as REDD+ forest areas (Covington et al., 2009). Consequently, the selection of this definition of 'forest' effect other definitions related to REDD+ implementation, such as deforestation, forest degradation and REDD+. According to Ministry Regulation No. P.30/Menhut-II/2009, deforestation, forest degradation and REDD+are defined as follows:

10. Deforestation is permanent change of forestland to non-forestland due to human induced activities.

11. Forest degradation is reduction of forest cover and carbon stock in a certain periods due to human induced activities. 
12. REDD is all efforts in forest management in order to stop and or reduce the decrease of forest cover and carbon stocks through various activities to support sustainable national development'. (Dephut, 2009, p. 2).

Indonesia has defined 'deforestation' based on land use status or ownership, rather than traditional forest criteria such as reduction of forest cover to a particular limit, such as defined by FAO (2006). This definition implies that deforestation conditions will only occur if the Ministry of Forestry has released forest title rights to other land users for other purposes. In this context, the Ministry of Forestry can state that there is no deforestation in the area, even though the forest area does not have trees anymore. Furthermore, there is time flexibility in both the deforestation and forest degradation definitions. Unlike CDM A/R, this regulation has applied vague words such as 'permanent' for deforestation and 'certain periods' for forest degradation. These ambiguities will create problems, for establishing the baseline and reference emission levels for such REDD+ projects. How long the historical deforestation information would be needed, and how long the periods of degradation would last, are questions for future project developers.

Unlike afforestation and reforestation under the Kyoto Protocol, which emphasizes efforts to convert non-covered forest area to covered forest area, the definition of REDD+ in Indonesia implies that REDD+ is applicable only to forestland areas (inside the forest boundary) because the definition relates to 'all efforts in forest management'. Article III(1) of this Ministry of Forestry regulation clearly describes the forest types that are eligible for REDD+ activities. This strict limitation of forest management boundaries will potentially limit the effort to attack the drivers of deforestation and forest degradation that usually occur outside of the forest management boundary. Other sectors including agriculture, mining and settlement are prominent sources of the drivers of deforestation, but will not be resolved as this definition has excluded them from REDD+ initiatives. Indonesia should consider the result of negotiations at COP15 required all developing countries to identify all drivers of deforestation and forest degradation, and address those drivers accordingly in the REDD+ implementation.

Another issue in relation to the boundary of 'forest management' in REDD+ concerns peatland management. Indonesia is known to have the third largest peatland area in the world (Joosten, 2009). However, the peatland is currently being heavily degraded due to development of canals, forest fires and forest conversion. This peatland degradation has emitted large amounts of GHGs, and Joosten (2009) claimed that Indonesian peatland is the largest source of GHG emissions in the world. Many peatland areas are located inside the forest boundary, but many of them are outside the boundary or across the boundary between forest and non-forest areas. If peatland is included in the future REDD+ framework, and considering that peatland in Indonesia exists not only in forest areas, the Government of Indonesia must be careful to avoid definitions that could potentially reduce the capacity of Indonesia to participate in global mitigation efforts. 


\section{CONCLUSION}

Discussion on forest definitions was set aside in the Cancun UNFCCC negotiations in December 2010. Some issues on the application of the Kyoto Protocol forest definitions into REDD+ initiatives have been raised by experts and the demand to review the current Kyoto's forest definition has escalated because it will be used for the future REDD+ implementation. The UNFCCC negotiators have only answered this plea indirectly through setting up some safeguards on REDD+ implementation. At the time of writing, it is unclear whether the discussion on forest definition will be conducted or forgotten in the next round of negotiation because there is no clear record specifically mentioning forest definition in the negotiation documents. On the other side, a common and broad forest definition that encompasses the range of forest types globally must be produced and agreed to allow the REDD+ mechanism to work internationally. In the international context, the definition must be flexible enough to acknowledge the variety of forest conditions and allow aggregation of comparable carbon emission efforts among countries. At a country level, each country must specify their forest definitions carefully considering the guidance provided at the global level and their own forest characteristics and management. Failure to do so could limit their involvement in future REDD+ mechanisms and reduce their capacity to mitigate climate change impacts.

Indonesia, as a case study, responded to this definition of forest issue by releasing their own forest definitions that are suitable for their own conditions. A few highlighted potential negative aspects of inappropriate forest definitions under REDD+ are identified in Indonesia including loss of opportunities to participate and gain benefit, inappropriate actions for remediation of forestry management, and possibly breaches of environmental integrity. When a country applies a broad forest definition, more detailed criteria and mechanisms for REDD+ implementation including the establishment of relevant local safeguards - should be imposed to avoid unnecessary consequences locally that influence overall efforts to reduce carbon emissions globally.

\section{REFERENCES}

BLEANEY, A., PESKETT, L. and D. MWAYAFU. 2010. REDD-plus after Copenhagen: what does it mean on the ground? REDD-NET COP15 Briefing. http://www.recoftc.org/site/uploads/content/pdf/REDD-net_COP15Briefing_64.pdf. Accessed 28 August 2011.

CADMAN, S. 2008. Defining Forests under the Kyoto Protocol: a way forward. http://unfccc.int/files/methods_science/redd/application/pdf/seancadman1_12nov08 .pdf. Accessed 28 August 2011.

COVINGTON, BAKER and MCKENZIE. 2009. Background Analysis of REDD Regulatory Framework. The Terrestrial Carbon Group and UN-REDD Programme. http://www.terrestrialcarbon.org/site/DefaultSite/filesystem/documents/TCG-2009Background-Analysis-of-REDD-Regulatory-Frameworks.pdf. Accessed 28 August 2011. 
DEPHUT (DEPartemen KeHUTanan or MINISTRY OF FORESTRY). 2009. Peraturan Menteri Kehutanan Republik Indonesia Nomor: P.30/Menhut-II/2009 tentang Tata Cara Pengurangan Emisi dari Deforestasi dan Degradasi Hutan (REDD). Departemen Kehutanan, Jakarta.

FAO (FOOD AND AGRICULTURE ORGANIZATION OF THE UNITED NATIONS). 2006. Global Forest Resource Assessment 2005 - Progress towards Sustainable Forest Management. FAO, Rome.

HELMS, J.A. 2002. What do these terms mean? Forest, forestry, forester. Journal of Forestry. 100(8): 15-15.

IPCC (INTERGOVERNMENTAL PANEL ON CLIMATE CHANGE). 2006. 2006 IPCC Guidelines for National Greenhouse Gas Inventories. Hayama, Japan: IGES.

JOOSTEN, H. 2009. The Global Peatland CO2 Picture: Peatland Status and Drainage Related Emissions in All Countries of the World. Wetlands International, Wageningen, the Netherlands.

LAMBRECHTS, C., WILKIE, M.L., RUCESKA, L. and M. SEN (editors) 2008. Vital Forest Graphics: Stopping the Downswing? UNEP/GRID-Arendal. http://www.grida.no/_res/site/file/publications/vital_forest_graphics.pdf. Accessed 28 August 2011.

LUND, H.G. 2005. Consideration for Developing U.S. Standard Definitions of Forest and Rangeland. Meridian Institute, Dillon, USA.

LUND, H.G. 2009. Definitions of Forest, Deforestation, Afforestation, and Reforestation. http://home.comcast.net/ gyde/DEFpaper.htm. Accessed 28 August 2011.

NEEFF, T., LUEPKE, H.V. and D. SCHOENE. 2006. Choosing a Forest Definition for the Clean Development Mechanism. FAO, Rome.

ROSOMAN, G., COTTER, J. and M. MARAHRENS. 2009. Why logging will not save the climate: The fallacy of GHG emissions reductions from so-called 'Sustainable Forest Management' (SFM) or Reduced Impact Logging (RIL) of natural forest. Greenpeace Research Laboratories Technical Note. Amsterdam. http://www.greenpeace.org/raw/content/international/press/reports/why-loggingwill-not-save-the.pdf. Accessed 28 August 2011.

SAZAKI, N. and F. PUTZ (2009). Critical need for new definitions of 'forest' and 'forest degradation' in global climate change agreements. Conservation. 2(5): 226-232.

UNFCCC (UNITED NATIONS FRAMEWORKS ON CLIMATE CHANGE CONVENTION). 2001. Report of the Conference of the Parties on its Seventh Session, held at Marrakesh held from 29 October to 10 November 2001. Addendum-Part Two: Action Taken by the Conference of the Parties. Volume IDecision 11/CP.7. http://unfccc.int/resource/docs/cop7/13a01.pdf\#page=64. Accessed 28 August 2011.

UNFCCC. 2010. Decision 1/16 The Cancun Agreements: Outcome of the Work of the Ad Hoc Working Group on Long-term Cooperative Action under the Convention. http://unfccc.int/resource/docs/2010/cop16/eng/07a01.pdf\#page=2. Accessed 28 August 2011.

VAN NOORDWYK, M. 2008. A submission to the UNFF Secretariat Online Forum on Forests and Climate Change. http://www.redd-monitor.org/2008/11/03/what-is-aforest/. Accessed 28 August 2011. 
VAN NOORDWIJK, M., AGUS, F., DEWI, S., EKADINATA, A., TATA, H.L., SUYANTO, GALUDRA, G., and U.P. PRADHAN. 2010. Opportunities for Reducing Emissions from All Land Uses in Indonesia: Policy Analysis and Case Studies. Partnership for the Tropical Forest Margins. ASB, Nairobi, Kenya. 